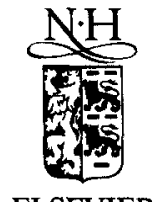

\title{
Fabrication of fine lead metaniobate powder using hydrothermal processes
}

\author{
Chung-Hsin Lu * Ning Chyi \\ Department of Chemical Engineering, National Taiwan University, Taipei, Taiwan. ROC \\ Received 9 May 1996; accepted 15 May 1996
}

\begin{abstract}
Fine submicron $\mathrm{PbNb}_{2} \mathrm{O}_{6}$ powder was successfully prepared from hydrothermally derived precursors. Through using lead nitrate and niobium hydrogenoxalate solutions as starting materials and heating the $200^{\circ} \mathrm{C}$-hydrothermally treated precursors at $800^{\circ} \mathrm{C}$ resulted in the complete formation of $\mathrm{PbNb}_{2} \mathrm{O}_{6}$. The particles exhibited a spherical shape. On the other hand, adding an ammonia solution in the hydrothermal process led to the formation of a pyrochlore phase. The well-developed crystallinity of the pyrochlore tended to retard the formation of $\mathrm{PbNb}_{2} \mathrm{O}_{6}$, and caused the reaction to be incomplete. Choosing appropriate starting materials was found to be crucial for controlling the reaction processes and microstructures of $\mathrm{PbNb}_{2} \mathrm{O}_{6}$ powder.
\end{abstract}

PACS: 77.84-S; 77.84 Dy

Keywords: Hydrothermal; Preparation; Powder; $\mathrm{PbNb}_{2} \mathrm{O}_{6}$; Piezoelectric; Pyrochlore; Ceramics

\section{Introduction}

Lead metaniobate, $\mathrm{PbNb}_{2} \mathrm{O}_{6}$, an important piezoelectric material, possesses a high Curie temperature, a very low mechanical $Q$, as well as a large $d_{33} / d_{31}$ ratio [1]. Because of its remarkable characteristics, $\mathrm{PbNb}_{2} \mathrm{O}_{6}$ is considered to be superior to PZT ceramics for use in hydrostatic pressure detectors. $\mathrm{PbNb}_{2} \mathrm{O}_{6}$ can exist in three polymorphs: rhombohedral, tetragonal and orthorhombic. The former two are stable crystalline structures and the transition temperature between them is about $1150^{\circ} \mathrm{C}$, while the last one is a metastable form $[2,3]$. In the past, lead metaniobate

\footnotetext{
${ }^{*}$ Corresponding author.
}

ceramics have been prepared by solid-state reaction [4] and molten-salt synthesis [5]. During the early 1990's, the alkoxy-derived method [6] and liquid phases coating technology [7] have also been used. However, the hydrothermal process for synthesizing $\mathrm{PbNb}_{2} \mathrm{O}_{6}$ has not yet been reported in the literature. The hydrothermal process has been confirmed to have advantages over conventional processes in enhancing the reaction rate of the reactants, and in reducing the size of particles formed, thereby increasing the sinterability of particles [8-10]. Furthermore, the evaporation and loss of volatile species such as lead can be avoided since the reactions take place in a closed system.

The purpose of this study was to synthesize $\mathrm{PbNb}_{2} \mathrm{O}_{6}$ powder through using a hydrothermal process. Three kinds of starting materials were utilized 
to prepare the precursors of $\mathrm{PbNb}_{2} \mathrm{O}_{6}$ under hydrothermal conditions. The hydrothermally obtained precursors were heated at various temperatures for investigating the formation processes of $\mathrm{PbNb}_{2} \mathrm{O}_{6}$. Furthermore, the effects of various starting materials on phase formation and the morphology of the obtained powder were also studied.

\section{Experimental}

Three different processes were utilized for preparing $\mathrm{PbNb}_{2} \mathrm{O}_{6}$ powder. In processes $\mathrm{A}$ and $\mathrm{B}$, reagent grade lead acetate and niobium hydrogenoxalate were used as raw materials. Each chemical was individually dissolved in distilled water to prepare the aqueous solution containing the specific cation. In process $\mathrm{A}$, the aqueous solutions were directly mixed together at a molar ratio of $\mathrm{Pb}^{2+}: \mathrm{Nb}^{5+}=1: 2$. As soon as the mixing process was undertaken, white $\mathrm{PbC}_{2} \mathrm{O}_{4}$ precipitates formed immediately. Then the precipitates along with the solution were introduced into a teflon-lined autoclave apparatus, and hydrothermally heated at 150 and $200^{\circ} \mathrm{C}$ for $2 \mathrm{~h}$. During the hydrothermal reaction, a mechanical stirrer was used to completely disperse the precipitates in solution. After the hydrothermal treatment, the products were filtrated and separated from the solution, and dried at around $60^{\circ} \mathrm{C}$. In process $\mathrm{B}$, after the lead and niobium solutions were mixed together, an ammonia solution was introduced into the mixed solutions until the $\mathrm{pH}$ value increased to around 10 . The mixed solutions were hydrothermally treated at $200^{\circ} \mathrm{C}$ for $2 \mathrm{~h}$, and dried as in process A. As for process $\mathrm{C}$, lead acetate was substituted by lead nitrate as a starting material. The temperature of the hydrothermal reaction in process $\mathrm{C}$ was $200^{\circ} \mathrm{C}$, and the other procedures were the same as in process $\mathrm{A}$.

In order to facilitate the formation of $\mathrm{PbNb}_{2} \mathrm{O}_{6}$, the hydrothermally obtained precursors in each process were calcined in air at temperatures ranging from 500 to $900^{\circ} \mathrm{C}$ for $2 \mathrm{~h}$. The compounds present in the precursors and the calcined specimens were characterized by $\mathrm{X}$-ray powder diffraction (XRD) using $\mathrm{Cu} K \alpha$ radiation. Scanning electron microscopy (SEM) was used to examine the microstructural evolution of the obtained specimens.

\section{Results and discussion}

In process $\mathrm{A}$, the mixed aqueous solutions were hydrothermally heated at 150 and $200^{\circ} \mathrm{C}$ for $2 \mathrm{~h}$, respectively. The XRD patterns of the as-received products are depicted in Fig. 1. As shown in Fig. 1a, the product obtained after the hydrothermal treatment at $150^{\circ} \mathrm{C}$ was crystalline $\mathrm{PbC}_{2} \mathrm{O}_{4}$. After the $200^{\circ} \mathrm{C}$-hydrothermal reaction, no new compound was generated, except that $\mathrm{PbC}_{2} \mathrm{O}_{4}$ became partially decomposed (see Fig. 1b). The above two hydrothermally treated precursors were then heated at $900^{\circ} \mathrm{C}$ for $2 \mathrm{~h}$. Fig. 1c and $1 \mathrm{~d}$ indicate that a medium amount of $\mathrm{PbNb}_{2} \mathrm{O}_{6}$ was formed in both specimens; however, a large amount of a compound having a pyrochlore-type structure and a small amount of an unknown phase also coexisted with $\mathrm{PbNb}_{2} \mathrm{O}_{6}$. These results reveal that the pure $\mathrm{PbNb}_{2} \mathrm{O}_{6}$ could not be acquired through this processing.

Comparing Fig. 1c with $1 \mathrm{~d}$, it is found that raising the hydrothermal temperature from 150 to $200^{\circ} \mathrm{C}$ increased the yield of $\mathrm{PbNb}_{2} \mathrm{O}_{6}$. In the hydrothermal treatment, the precursors formed during hydrothermal reactions needed to be separated from the solu-

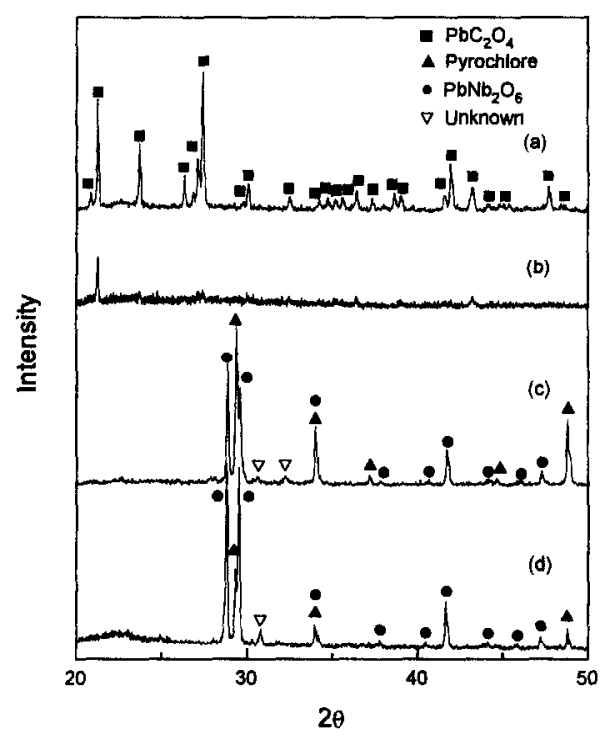

Fig. 1. X-ray diffraction patterns of the specimens obtained from process A. (a) and (b): the as-received precursors after the hydrothermal reaction at $150^{\circ} \mathrm{C}$ and $200^{\circ} \mathrm{C}$ for $2 \mathrm{~h}$, respectively. (c) and (d): the (a) and (b) precursors calcined at $900^{\circ} \mathrm{C}$ for $2 \mathrm{~h}$, respectively. 
tion. When the temperature of hydrothermal reactions was low, a large amount of niobium ions that did not incorporate into the precursors still remained in the solution. Hence, the removal of the solution containing niobium ions led to a stoichiometric deviation, thereby causing the incomplete formation of $\mathrm{PbNb}_{2} \mathrm{O}_{6}$. Once the hydrothermal temperature was increased, the ratio of niobium ions in precursors would be increased, and more $\mathrm{PbNb}_{2} \mathrm{O}_{6}$ can be produced. The failure of preparing $\mathrm{PbNb}_{2} \mathrm{O}_{6}$ in process $\mathrm{A}$ is considered to be mainly attributed to the loss of niobium ions in the solutions. Therefore, how to keep niobium ions incorporated in the hydrothermally formed precursors is important for synthesizing pure $\mathrm{PbNb}_{2} \mathrm{O}_{6}$.

In a previous study [11], adding ammonium to lead and niobium-containing solutions was found to directly generate a pyrochlore compound $\mathrm{Pb}_{2} \mathrm{Nb}_{2} \mathrm{O}_{7}$ via a hydrothermal process at $150^{\circ} \mathrm{C}$. Once the pyrochlore is formed, niobium ions will be incorporated into precursors and the stoichiometry can be maintained. In process $\mathrm{B}$, for forming a pyrochlore phase during hydrothermal reactions, an ammonia solution was introduced to the system of the lead acetate and niobium hydrogenoxalate aqueous solutions. After the hydrothermal treatment at $200^{\circ} \mathrm{C}$ for $2 \mathrm{~h}$, a pure pyrochlore compound having a high crystallinity was formed (see Fig. 2a). It is found that the X-ray diffraction pattern of the pyrochlore phase formed in process $\mathrm{B}$ shifted to the high angle side in comparison with that of $\mathrm{Pb}_{2} \mathrm{Nb}_{2} \mathrm{O}_{7}$. This phenomenon indicates the reduction of the lattice constant in the former pyrochlore phase. In Yamaguchi's experiment [6], an intermediate compound having the pyrochlore structure also existed during the formation processes of $\mathrm{PbNb}_{2} \mathrm{O}_{6}$ when alkoxy derived precursors were used.

The precursors obtained in process $\mathrm{B}$ were calcined at various temperatures for investigating the reaction processes for forming $\mathrm{PbNb}_{2} \mathrm{O}_{6}$. The XRD data for the calcined specimens are illustrated in Fig. $2 \mathrm{~b}$ to $2 \mathrm{e}$. The pyrochlore phase was found to maintain its structure stably upon heating up to $600^{\circ} \mathrm{C}$; however, from $700^{\circ} \mathrm{C}$ the conversion reaction of pyrochlore to $\mathrm{PbNb}_{2} \mathrm{O}_{6}$ started. With increasing the calcination temperature, the amount of $\mathrm{PbNb}_{2} \mathrm{O}_{6}$ increased along with the consumption of the pyrochlore phase. After calcination at $900^{\circ} \mathrm{C}$ for $2 \mathrm{~h}$, a

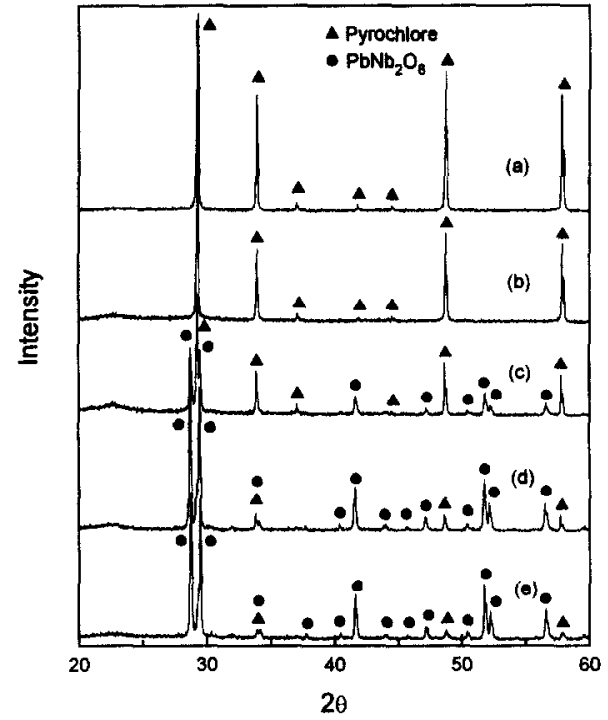

Fig. 2. X-ray diffraction patterns of the specimens obtained from process $B$. (a) The hydrothermally derived precursors at $200^{\circ} \mathrm{C}$, and the precursors calcined at (b) $600^{\circ} \mathrm{C}$, (c) $700^{\circ} \mathrm{C}$, (d) $800^{\circ} \mathrm{C}$, and (e) $900^{\circ} \mathrm{C}$, respectively.

large amount of $\mathrm{PbNb}_{2} \mathrm{O}_{6}$ was formed; however, a small amount of the parasite pyrochlore phase still remained in the specimen, revealing that the formation of $\mathrm{PbNb}_{2} \mathrm{O}_{6}$ was incomplete.

In the third process $\mathrm{C}$, lead nitrate rather than lead acetate was used as a lead source. The XRD patterns of the hydrothermally derived and subsequently calcined specimens are shown in Fig. 3. The reaction scheme of the precursors obtained in process $C$ was found to be distinctly different from that in process B. The product obtained after a hydrothermal treatment of $200^{\circ} \mathrm{C}$ is thought to contain partially decomposed $\mathrm{PbC}_{2} \mathrm{O}_{4}$ (see Fig. 3a). After $500^{\circ} \mathrm{C}$-calcination, a small amount of the pyrochlore phase having a broaden diffraction pattern was formed (see Fig. $3 \mathrm{~b}$ ). Judging from the low crystallinity of the pyrochlore, it is clear that the formation of the pyrochlore phase was in a very initial stage. When the temperature reached $600^{\circ} \mathrm{C}, \mathrm{PbNb}_{2} \mathrm{O}_{6}$ started to form. At this temperature, the pyrochlore phase also coexisted with $\mathrm{PbNb}_{2} \mathrm{O}_{6}$ (see Fig. 3c). On increasing the calcination temperature up to $800^{\circ} \mathrm{C}$, the pyrochlore phase entirely disappeared, and pure $\mathrm{PbNb}_{2} \mathrm{O}_{6}$ was formed. The obtained $\mathrm{PbNb}_{2} \mathrm{O}_{6}$ exhibited a rhombohedral symmetry (see Fig. 3e), and the lattice spac- 


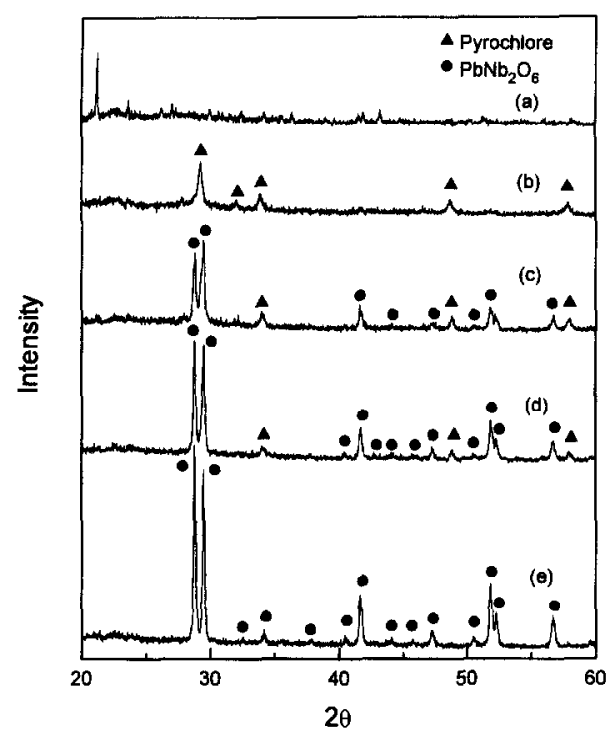

Fig. 3. X-ray diffraction patterns of the specimens obtained from process $\mathrm{C}$. (a) The hydrothermally derived precursors at $200^{\circ} \mathrm{C}$, and the precursors calcined at (b) $500^{\circ} \mathrm{C}$, (c) $600^{\circ} \mathrm{C}$, (d) $700^{\circ} \mathrm{C}$, and (e) $800^{\circ} \mathrm{C}$, respectively.

ings obtained for $\mathrm{PbNb}_{2} \mathrm{O}_{6}$ were in good agreement with that reported in JCPDS File: PDF 11-122 [12]. When the specimen was cooled down after being heated to $1250^{\circ} \mathrm{C}$, an orthorhombic phase was formed as reported in the literature [6]. On comparing the above two processes $B$ and $C$, it is found that the pyrochlore phase produced in process $\mathrm{B}$ exhibited a much better crystallinity than that in process $\mathrm{C}$. Moreover, in process $\mathrm{B}$ the initial formation temperature of $\mathrm{PbNb}_{2} \mathrm{O}_{6}$ was $100^{\circ} \mathrm{C}$ higher than that in process $\mathrm{C}$. It seems that the tight bonding of the well-crystallized pyrochlore phase formed in process $B$ would retard the formation of $\mathrm{PbNb}_{2} \mathrm{O}_{6}$, and caused the formation of $\mathrm{PbNb}_{2} \mathrm{O}_{6}$ to be incomplete. On the contrary, the loosely bound structure of the pyrochlore phase formed in process $\mathrm{C}$ enabled the conversion of the pyrochlore phase into $\mathrm{PbNb}_{2} \mathrm{O}_{6}$ to progress smoothly.

The microstructures of the obtained precursors and calcined specimens from processes $\mathrm{B}$ and $\mathrm{C}$ are shown in Fig. 4. The hydrothermally prepared particles from process $B$ exhibited a polyhedral shape (see Fig. 4a). This shape of particles reflected the idiomorphic morphology of the pyrochlore phase. Among the polyhedrons, a small region exhibiting a fluffy morphology is regarded as the unreacted species. After calcination at $800^{\circ} \mathrm{C}$ for $2 \mathrm{~h}$, the sharp edges of the polyhedron became rounded, but the

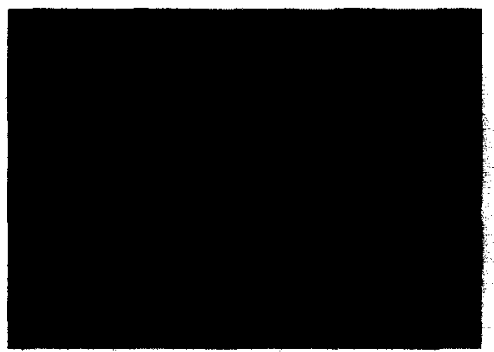

(a)

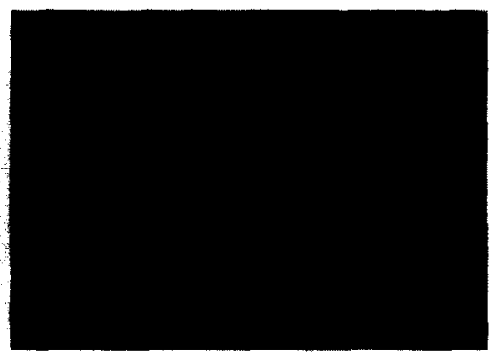

(b)

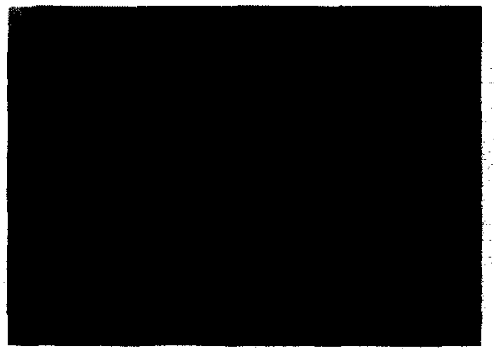

(c)
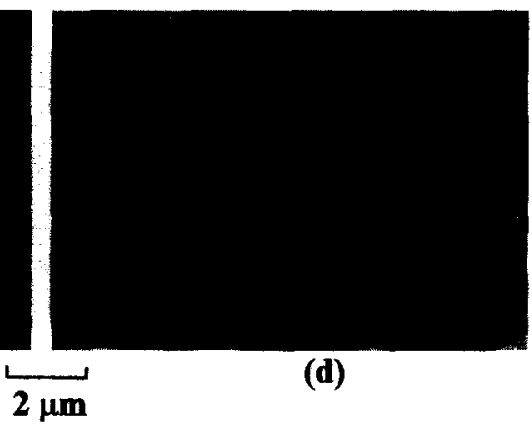

(d)

Fig. 4. Scanning electron micrographs of the specimens obtained in process $\mathrm{B}$ after (a) $200^{\circ} \mathrm{C}$-hydrothermal reaction and (b) calcination at $800^{\circ} \mathrm{C}$, and the specimens obtained in process $\mathrm{C}$ after (c) $200^{\circ} \mathrm{C}$-hydrothermal reaction and (d) calcination at $800^{\circ} \mathrm{C}$. 
contour of the calcined powder still partly resembled that of the hydrothermally derived precursors (see Fig. 4b). After calcination, the particle size was estimated to be about $1.0 \mathrm{~mm}$. On the other hand, the precursors prepared via process $\mathrm{C}$ exhibited a spherical shape and a more uniform microstructure as shown in Fig. 4c. The difference between the precursors obtained in processes $\mathrm{B}$ and $\mathrm{C}$ is mainly attributed to the different phases formed during hydrothermal reactions. When the precursors obtained in process $\mathrm{C}$ were calcined at $800^{\circ} \mathrm{C}$ for $2 \mathrm{~h}$, part of grains were slightly sintered, but the majority of the grains maintained the spherical morphology with a submicron size (see Fig. 4d). It is evident that different starting materials and preparation procedures used in the hydrothermal processes significantly influenced the morphology of the precursors, thereby resulting in various microstructures of the final products.

\section{Conclusions}

(1) When lead acetate and niobium hydrogenoxalate solutions were used as starting materials, pure lead metaniobate $\mathrm{PbNb}_{2} \mathrm{O}_{6}$ could not be prepared through heating the hydrothermally derived precursors due to the loss of niobium cations in solutions.

(2) Once an ammonium solution was added to the above lead and niobium containing solutions, a pyrochlore phase having a well-developed crystallinity was directly produced after the hydrothermal reaction at $200^{\circ} \mathrm{C}$. The pyrochlore phase exhibited an idiomorphic morphology and tended to retard the formation of $\mathrm{PbNb}_{2} \mathrm{O}_{6}$.

(3) When lead nitrate and niobium hydrogenoxalate solutions were used, heating the $200^{\circ} \mathrm{C}$-hydrothermally treated precursors at $800^{\circ} \mathrm{C}$ for $2 \mathrm{~h}$ resulted in the complete formation of $\mathrm{PbNb}_{2} \mathrm{O}_{6}$. The obtained particles exhibited a spherical shape with a submicron particle size. $\mathrm{It}$ is concluded that choosing appropriate starting materials and preparation procedures is crucial for controlling the reaction processes and microstructures of $\mathrm{PbNb}_{2} \mathrm{O}_{6}$ powder.

\section{References}

[1] M. Granahan, M. Holmes, W.A. Schulze and R.E. Newnham, J. Am. Ceram. Soc. 64 (1981) C68.

[2] M.H. Francombe, Acta Cryst. 9 (1956) 683.

[3] R.S. Roth, J. Res. Natl. Bur. Stand. 62 (1959) 27.

[4] G. Goodman, J. Am. Ceram. Soc. 36 (1953) 368.

[5] T. Kimura, M. Machida, and T. Yamaguchi, J. Am. Ceram. Soc. 66 (1983) C195.

[6] O. Yamaguchi and Y. Mukaida, J. Mater. Sci. Lett. 9 (1990) 556.

[7] C. Li, H. Ni, Y. Lu and Z. Yin, J. Inorg. Mater. 8 (1993) 44.

[8] W.J. Dawson, Am. Ceram. Soc. Bull. 67 (1988) 1673.

[9] K. Fukai, K. Hidaka, M. Aoki and K. Abe, Ceram. Inter. 16 (1990) 285 .

[10] C.H. Lu and W.J. Hwang, Mater. Lett., in press.

[11] C.H. Lu and S.Y. Lo, Mater. Res. Bull., submitted for publication.

[12] Powder Diffraction File, Card No. 29-780. Joint Committee on Powder Diffraction Standards, Swarthmore, PA. 